\title{
Histone Deacetylases Promote ER Stress Induced Epithelial Mesenchymal Transition in Human Lung Epithelial Cells
}

\author{
Daishun Liu Honglan Zhu Ling Gong Shenglan Pu Yang Wu Wei Zhang \\ Guichuan Huang
}

Department of Respiratory Medicine, The First People's Hospital of Zunyi, The Third Affiliated Hospital of Zunyi Medical College, Institute of Respiratory Diseases in Zunyi, Zunyi, Guizhou, China

\section{Key Words}

Histone deacetylase - Endoplasmic reticulum stress - Epithelial-mesenchymal transition • Pulmonary fibrosis

\begin{abstract}
Background/Aims: Epithelial to mesenchymal transition (EMT) is a crucial process involved in pulmonary fibrosis. This study aimed to explore the role of histone deacetylases (HDACs) and endoplasmic reticulum (ER) stress in EMT in human lung epithelial cells. Methods: Human lung adenocarcinoma A549 cells were treated with bleomycin and tunicamycin to induce EMT. The proliferation of A549 cells was detected by MTT assay. The expression of HDACs and EMT markers was detected by PCR and Western blot analysis. The secretion of TGF- $\beta 1$ and collagen I was examined by ELISA. Results: A549 cells switched from a cobblestone-like appearance to an elongated fibroblast like appearance after exposure to tunicamycin or bleomycin, accompanied by increased expression of $\mathrm{N}$-cadherin, $\alpha$-SMA and Collagen I. Meanwhile, GRP78 was upregulated in A549 cells exposed to tunicamycin or bleomycin. These changes induced by tunicamycin or bleomycin could be abrogated by 4-PBA. Moreover, tunicamycin and bleomycin promoted the expression of HDAC2 and HDAC6, and HDACs inhibitor SAHA abrogated the morphological and biochemical changes in A549 cells. 4-PBA and SAHA inhibited the upregulation of pulmonary fibrosis factors TGF- $\beta 1$ and IL-32 and the activation of Smad pathway induced by tunicamycin or bleomycin. Conclusions: We provide the first evidence that tunicamycin and bleomycin induce ER stress and EMT in lung epithelial cells via the upregulation of HDACs. HDACs inhibitor could inhibit ER stress induced upregulation of pulmonary fibrosis factors and the activation of Smad pathway. HDACs inhibitors are promising agents for the therapy of pulmonary fibrosis.

\section{Introduction}

Idiopathic pulmonary fibrosis (IPF) is a chronic progressive lung disease of unknown etiology. Once the patients are diagnosed as IPF, their median survival is only 3-4 years, and 


\section{Cellular Physiology Cell Physiol Biochem 2018;46:1821-1834 \\ \begin{tabular}{c|c} 
and Biochemistry Published online: April 30, 2018 & $\begin{array}{l}\text { (c) 2018 The Author(s). Published by S. Karger AG, Basel } \\
\text { www.karger.com/cpb }\end{array}$ \\
\hline
\end{tabular}}

Liu et al.: HDACs Promotes EMT of Lung Epithelium

the mortality rate is higher than many cancers $[1,2]$. At present the etiology and pathogenesis of IPF is still not clear, and the efficacy for the treatment of IPF is low [3]. Therefore, further understanding of molecular mechanism of IPF will be important to develop novel and effective strategies for the prevention and therapy of IPF.

The pathogenic process of IPF involves the disturbed balance of the apoptosis and proliferation of fibroblast as well as the overproduction of extracellular matrix (ECM) components such as collagen [4]. Myofibroblast is an important source for the synthesis of collagen, and epithelial-to-mesenchymal transition (EMT) plays important role in the regulation of myofibroblast $[5,6]$. EMT refers to the phenomenon that epithelial cells stimulated by certain stimuli obtain mesenchymal cell phenotypes and physiological characteristics such as the change of cell morphology from flat epithelial cells into spindleshaped fibroblasts, reduced expression of E-cadherin and increased expression of $\mathrm{N}$-cadherin, $\alpha$-SMA, Collagen I and Collagen III [7]. However, the role of EMT in IPF is unclear.

Recent studies suggest that several factors such as smoking, chronic aspiration and viral infection could potentially result in endoplasmic reticulum stress (ER stress) of type II alveolar epithelial cells and ultimately leads to the apoptosis and EMT of these cells [810]. The stimulation by tunicamycin, thapsigargin and bleomycin could induce ER stress and promote EMT of AEC II and renal tubular epithelial cells, but 4-phenyl-butyric acid (4-PBA) inhibited the activation of ER stress and the induction of EMT [11-14].

Histone deacetylases (HDACs) participate in the regulation of dynamic equilibrium state of histone or non-histone acetylation/deacetylation and their deacetylase activity could be inhibited by histone deacetylase inhibitor (HDACi). Recent studies have shown that HDACs are involved in the formation of EMT and the induction of ER stress [15-20]. However, whether HDACs affect ER stress and EMT of lung epithelial cells during the development of pulmonary fibrosis needs to be explored.

In this study, we employed tunicamycin and bleomycin to induce ER stress in human lung epithelial cells and used HDACi to investigate the role of HDACs in the modulation of ER stress and EMT of human lung epithelium and in the pathogenesis of pulmonary fibrosis.

\section{Materials and Methods}

\section{Cell culture and treatment}

Human lung adenocarcinoma A549 cells were purchased from American Type Culture Collection (ATCC CRM-CCL-185TM), and cultured in RPMI1640 medium supplemented with 10\% fetal bovine serum (FBS) at $37^{\circ} \mathrm{C}$ in $5 \% \mathrm{CO}_{2}$ incubator. Cells were cultured for $24 \mathrm{~h}$, serum starved for $24 \mathrm{~h}$, then treated with $0.5 \mu \mathrm{g} / \mathrm{ml}$ tunicamycin or bleomycin, or different concentrations of 4-PBA or HDACi suberoylanilide hydroxamic acid (SAHA) for different period.

\section{MTT assay}

A549 cells were seeded into 96-well plates at a density of 5, 000 cells/well, cultured in a humidified chamber at $37^{\circ} \mathrm{C}$ overnight and then treated with tunicamycin or bleomycin. Each day for six consecutive days, viable cells were evaluated with MTT assay kit (Sigma, USA) according to the manufacturer's instructions. $20 \mu \mathrm{L}$ MTT ( $5 \mathrm{mg} / \mathrm{mL}$ ) solution was added to each well and the plates were incubated at $37^{\circ} \mathrm{C}$ for $4 \mathrm{~h}$, then $150 \mu \mathrm{L}$ DMSO was added to each well and the plates were incubated at room temperature for $10 \mathrm{~min}$. The absorption value of every well (A) was read at $490 \mathrm{~nm}$ using a microplate reader (ELX800, Bio-Tek, USA).

\section{RT-PCR}

Total RNA was extracted from A549 cells by using RNAsi plus (Takara) according to the instructions, and the integrity of total RNA was confirmed by spectrophotometer. Total RNA was reversely transcribed into cDNA using reverse transcription kit (Takara), and PCR was performed with cDNA as the template under the conditions: $94^{\circ} \mathrm{C}$ for $1 \mathrm{~min} ; 94^{\circ} \mathrm{C}$ for $30 \mathrm{sec}-52^{\circ} \mathrm{C}$ for $30 \mathrm{sec}-72^{\circ} \mathrm{C}$ for $1 \mathrm{~min}, 30 \mathrm{cycles} ; 72^{\circ} \mathrm{C}$ for $10 \mathrm{~min}$. All primers were purchased from Life Technologies (USA) and the sequences were as follows: GRP78 forward 5'-TATGTCGCCTTCACTCCTGA-3' reverse 5'-AGTTCCAGCGTCTTTGGTTG-3'; 
HDAC2 forward 5'- TGGCACAGGAGACTTGAGG-3' reverse 5'- TGTCCAACATCGAGCAACAT-3'; HDAC6 forward 5'- TGCTGAGTACGTGGGTCATC-3' reverse 5'-GGACATCCCAATCCACAATC-3'; N-cadherin forward 5'-AGGTTTGCCAGTGTGACTCC-3' reverse 5'- GGGTCTTTCATCCATTCGTC-3'; E-cadherin forward 5'-ACTGAATGGTCGGAATCACA-3' reverse 5'- CACAGCAATGAAACCTGAGC-3'; $\alpha$-SMA forward 5'-GTGACTACTGCCGAGCGTG-3' reverse 5'-ATAGGTGGTTTCGTGGATGC-3'; $\operatorname{smad2}$ forward 5'-TGGAGAAACAAGTGACCAACA-3' reverse 5'-GAGCCAGAAGAGCAGCAAAT-3'; smad3 forward 5'-GGGAGATGATGGGCTAAACA-3' reverse 5'-GCAGCAGTGAAGGTGAGTGA-3'; TGF- $\beta 1$ forward 5'-TGGTGGAAACCCACAACGAA-3' reverse 5'-CCGGTAGTGAACCCGTTGAT-3'; IL-32 forward 5'-GTCCTCTTTCCAGTCCTACGG-3' reverse 5'-ATCACCCAGTCTCAGGCATT-3'; IL-1 $\beta$ forward 5'-GAGCACCTTCTTTCCCTTCA-3' reverse $5^{\prime}$ - $\quad$ TCATCTTTCAACACGCAGGA-3'; $\beta$-actin forward 5'-AGCGAGCATCCCCCAAAGTT-3' reverse 5'-GGGCACGAAGGCTCATCATT-3'.

PCR products were run by $2 \%$ gel electrophoresis and stained with ethidium bromide. For quantitation of mRNA levels, real-time PCR was performed with $\beta$-actin as internal control and mRNA levels were calculated by the $2^{-\Delta \Delta \mathrm{Ct}}$ method. Each $\mathrm{Ct}$ value used for the calculations was the mean of the triplicate experiments.

\section{Western blot analysis}

Total proteins were isolated from A549 cells and quantitated by bicinchonic acid (BCA) method. 50 $\mu \mathrm{g}$ proteins were loaded onto $12 \%$ SDS-PAGE for the separation and transferred to PVDF membranes. The membranes were then incubated with specific antibody for GRP78, $\alpha$-SMA, HDAC2, HDAC6 or $\beta$-actin (Cell Signaling, Danvers, MA, USA) at $4^{\circ} \mathrm{C}$ overnight. The membranes were washed and incubated with HRP conjugated secondary antibodies for $2 \mathrm{~h}$ at room temperature. The membranes were exposed using ECL kit and the signals were analyzed with Quantity one 4.62 software. The experiments were repeated three times.

\section{ELISA}

The supernatants were collected from A549 cells and TGF- $\beta 1$ and collagen I contents in the supernatants were measured using kits (R\&D systems, Minneapolis, MN, USA) following the manufacturer's protocols.

\section{Statistical analysis}

Data were expressed as mean \pm SEM and analyzed by SPSS 22.0 statistical software. Comparisons between two groups were performed using T TEST, and comparisons among multiple groups were performed using one-way ANOVA followed by Tukey's post-hoc test. P $<0.05$ was considered statistically significant.

\section{Results}

Tunicamycin and bleomycin induce EMT of A549 cells

In order to find the optimal concentration and time for the treatment of A459 cells by tunicamycin and bleomycin without causing excessive cell death, different concentrations of tunicamycin and bleomycin $(0-10.0 \mu \mathrm{g} / \mathrm{ml})$ were used to treat A549 cells for $12 \mathrm{~h}, 24$ $\mathrm{h}, 48 \mathrm{~h}$ and $72 \mathrm{~h}$, and cell viability was detected by MTT assay. We found that tunicamycin or bleomycin inhibited the viability of A549 cells in a dose and time dependent manner (data not shown). Therefore, A549 cells were treated with three different concentrations of tunicamycin and bleomycin $(0.5,1.0,3.0 \mu \mathrm{g} / \mathrm{ml})$ for $48 \mathrm{~h}$, and we found cells elongated from the cobblestone shape (Fig. 1A red arrow). Because many cells died after treatment with 1.0 and $3.0 \mu \mathrm{g} / \mathrm{ml}$ tunicamycin and bleomycin, $0.5 \mu \mathrm{g} / \mathrm{ml}$ tunicamycin and bleomycin were selected to treat A549 cells for $24 \mathrm{~h}, 48 \mathrm{~h}$ and $72 \mathrm{~h}$, and we found cells elongated from the cobblestone shape at 48 and $72 \mathrm{~h}$ after treatment (Fig. 1B red arrow). The changes in A549 cell morphology indicated that mesenchymal change occurred after tunicamycin and bleomycin treatment.

To further explore whether tunicamycin and bleomycin induce EMT of A540 cells, we detected the expression of EMT-related molecules in A549 cells after tunicamycin and bleomycin treatment. We found that mRNA expression of mesenchymal marker N-cadherin 


\section{Cellular Physiology Cell Physiol Biochem 2018:46:1821-1834 \begin{tabular}{l|l} 
DOI: 10.1159/000489367 & $\begin{array}{l}\text { O 2018 The Author(s). Published by S. Karger AG, Basel } \\
\text { www.karger.com/cpb }\end{array}$ \\
\hline
\end{tabular} \\ Liu et al.: HDACs Promotes EMT of Lung Epithelium}

Fig. 1. Tunicamycin and bleomycin induce EMT in A549 cells. A: Phase contrast images of A549 cells treated with TM, BLM or vehicle control for $48 \mathrm{~h}$. B: Phase contrast images of A549 cells treated with 0.5 $\mu \mathrm{g} / \mathrm{ml} \mathrm{TM}$ or BLM for 0,24 , 48 and $72 \mathrm{~h}$. Magnification: x200. C, D: RT-PCR analysis of N-cadherin, $\alpha$-SMA and E-cadherin mRNA levels in A549 cells treated with TM $(0.5 \mu \mathrm{g} / \mathrm{ml})$, BLM $(0.5$ $\mu \mathrm{g} / \mathrm{ml}$ ) or vehicle control (DMSO) for 48 h. E, F: Western blot analysis of $\alpha$-SMA in A549 cells treated with TM $(0.5 \mu \mathrm{g} / \mathrm{ml})$, BLM $(0.5$ $\mu \mathrm{g} / \mathrm{ml}$ ) or vehicle control (DMSO) for 48 h. G: ELISA analysis of collagen I level

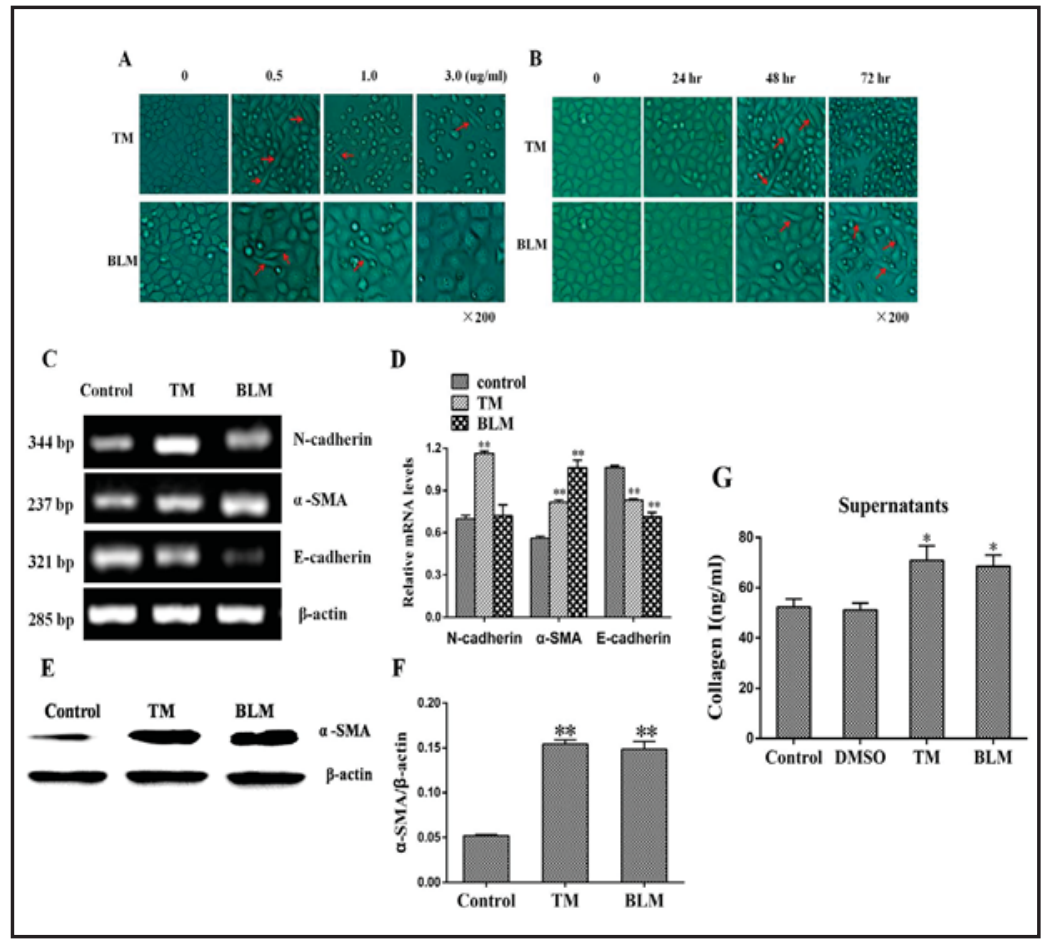
in the supernatant of A549 cells treated with TM $(0.5 \mu \mathrm{g} / \mathrm{ml})$, BLM $(0.5 \mu \mathrm{g} / \mathrm{ml})$, DMSO or control (untreated) for $48 \mathrm{~h}$. All data were from 3 separate experiments. ${ }^{*} \mathrm{p}<0.05,{ }^{* *} \mathrm{p}<0.01$ vs. control. TM: tunicamycin; BLM: bleomycin.

increased after tunicamycin treatment, mRNA and protein expression of $\alpha$-SMA increased after tunicamycin and bleomycin treatment, while mRNA expression of epithelial cell marker E-cadherin decreased after tunicamycin and bleomycin treatment (Fig. 1C, D, E, F). ELISA assay showed that tunicamycin and bleomycin increased the secretion of collagen I by A549 cells (Fig. 1G). Collectively, these data provide evidence that tunicamycin and bleomycin induce EMT in A549 cells.

\section{Tunicamycin and bleomycin induce ER stress in A549 cells}

To investigate whether tunicamycin and bleomycin induce ER stress in A549 cells, the expression of ER chaperone GRP78 mRNA was detected by RT-PCR. We found that treatment with A549 cells by tunicamycin or bleomycin at different concentration and different time period all led to increased expression of GRP78 mRNA compared to control (Fig. 2A, B, C, D).

Next we explored whether ER stress inhibitor 4-PBA could inhibit tunicamycin and bleomycin induced ER stress in A549 cells. A549 cells were treated with tunicamycin or bleomycin in combination with $0,0.5$, or $1.0 \mathrm{mM} 4-\mathrm{PBA}$, RT-PCR analysis showed that 4-PBA reduced GRP78 mRNA expression induced by tunicamycin or bleomycin in a dosedependent manner (Fig. 2E, F, I, J). A549 cells were then treated with tunicamycin or bleomycin in combination with $1.0 \mathrm{mM}$ 4-PBA. Western blot analysis showed that 4-PBA reduced GRP78 protein expression induced by tunicamycin and bleomycin, but there was no significant difference in GRP78 protein expression between control group and 4-PBA treated group (Fig. 2G, H, K, L). Taken together, these results suggest that tunicamycin and bleomycin induce ER stress in A549 cells.

ER stress mediates EMT in A549 cells

Since we showed that tunicamycin and bleomycin not only induce EMT but also induce ER stress in A549 cells, we wondered whether there is a correlation between ER stress and EMT. We used ER stress inhibitor 4-PBA to treat A549 cells together with tunicamycin or 


\section{Cellular Physiology Cell Physiol Biochem 2018;46:1821-1834

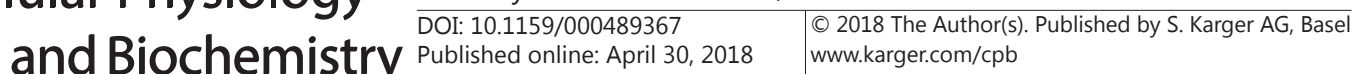

bleomycin, and detected cell morphological changes and the expression of EMT related molecules.

Compared to tunicamycin or bleomycin treated group, additional treatment with different concentrations $(0.5,1.0 \mathrm{mM})$ of 4-PBA led to reduced number of cells with elongated fibroblast cell morphology, while 4-PBA treated group showed no changes in cell morphology (Fig. 3A, B), indicating that 4-PBA suppressed tunicamycin or bleomycin induced mesenchymal change in A549 cells. Compared to tunicamycin or bleomycin treated group, $1.0 \mathrm{mM}$ 4-PBA decreased mRNA expression of mesenchymal markers $\mathrm{N}$-cadherin and $\alpha$-SMA (p <0.05) (Fig. 3C, D, E, F). 4-PBA also decreased protein expression of $\alpha$-SMA (p $<0.05$ ), but there was no significant difference in $\alpha$-SMA protein expression between control group and 4-PBA treated group (Fig. 3G, H, I, J). Furthermore, 4-PBA inhibited tunicamycin and bleomycin induced secretion of collagen I by A549 cells (Fig. 3K). These results suggest that ER stress mediates EMT of A549 cells.

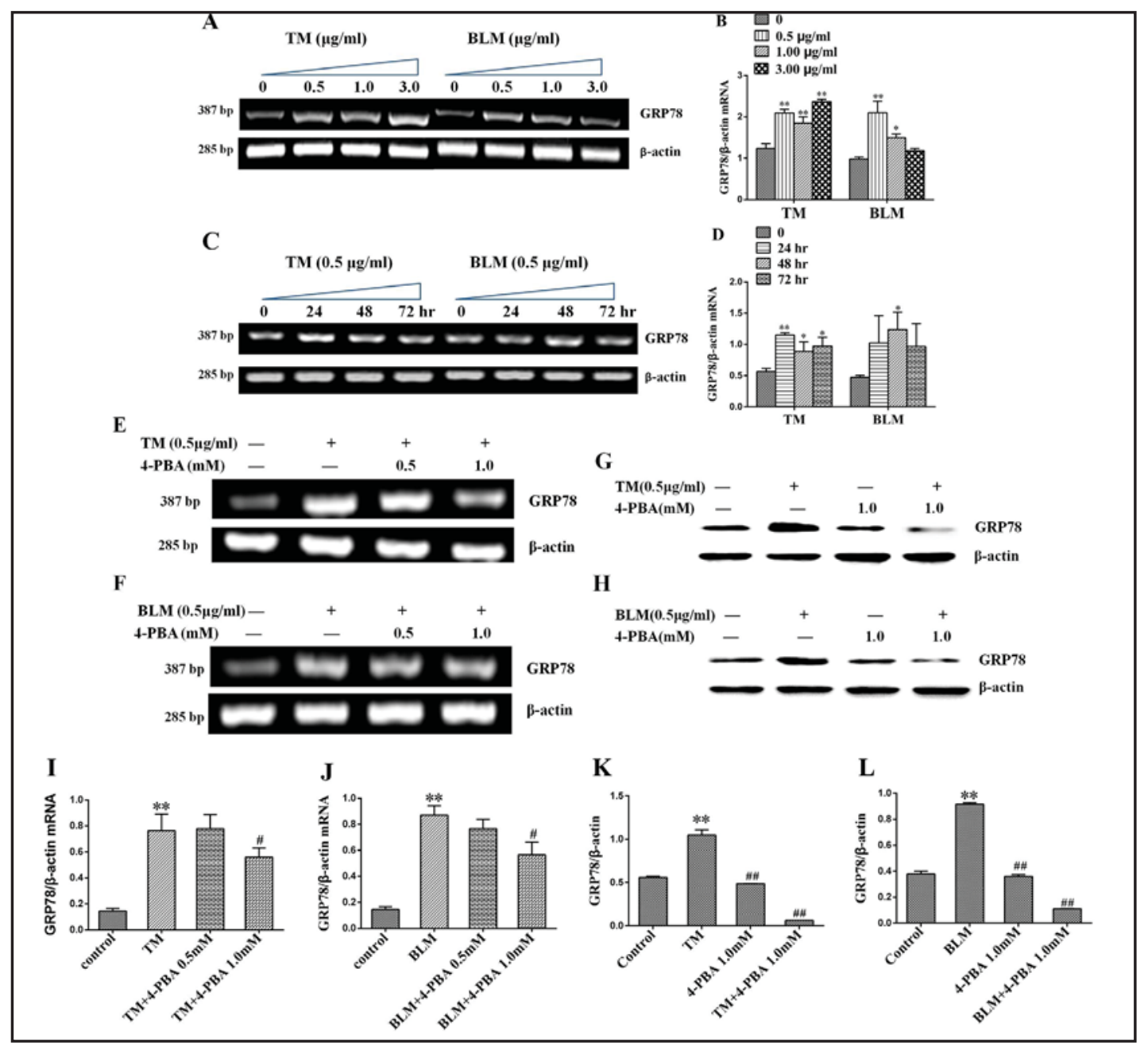

Fig. 2. Tunicamycin and bleomycin induce ER stress in A549 cells. A549 cells were plated in 6-well plates one day prior to treatment with TM or BLM, and cells were growth arrested in serum-free medium for $24 \mathrm{~h}$. A, B: RT-PCR analysis of GRP78 mRNA in A549 cells treated with TM, BLM or control for $48 \mathrm{~h}$. C, D: RT-PCR analysis of GRP78 mRNA levels in A549 cells treated with $0.5 \mu \mathrm{g} / \mathrm{ml}$ TM or BLM for 0, 24, 48 and $72 \mathrm{~h}$. E, F, I, J: RT-PCR analysis of GRP78 mRNA in A549 cells treated with TM or BLM for $48 \mathrm{~h}$ with or without pretreatment with 4-PBA. G, H, K, L: Western blot analysis of GRP78 protein levels in A549 cells treated with TM or BLM for $48 \mathrm{~h}$ with or without pretreatment with 4-PBA. All data were from 3 separate experiments. ${ }^{*} \mathrm{p}<0.05$, ${ }^{* *} \mathrm{p}<0.01$ vs. control. \#p<0.05, \#\#p<0.05 vs. TM or BLM. TM: tunicamycin; BLM: bleomycin. 


\section{Cellular Physiology Cell Physiol Biochem 2018;46:1821-1834 \begin{tabular}{l|l} 
DOI: 10.1159/000489367 & $\begin{array}{l}\text { () } 2018 \text { The Author(s). Published by S. Karger AG, Basel } \\
\text { www.kargercom/cpb }\end{array}$
\end{tabular} Liu et al.: HDACs Promotes EMT of Lung Epithelium}

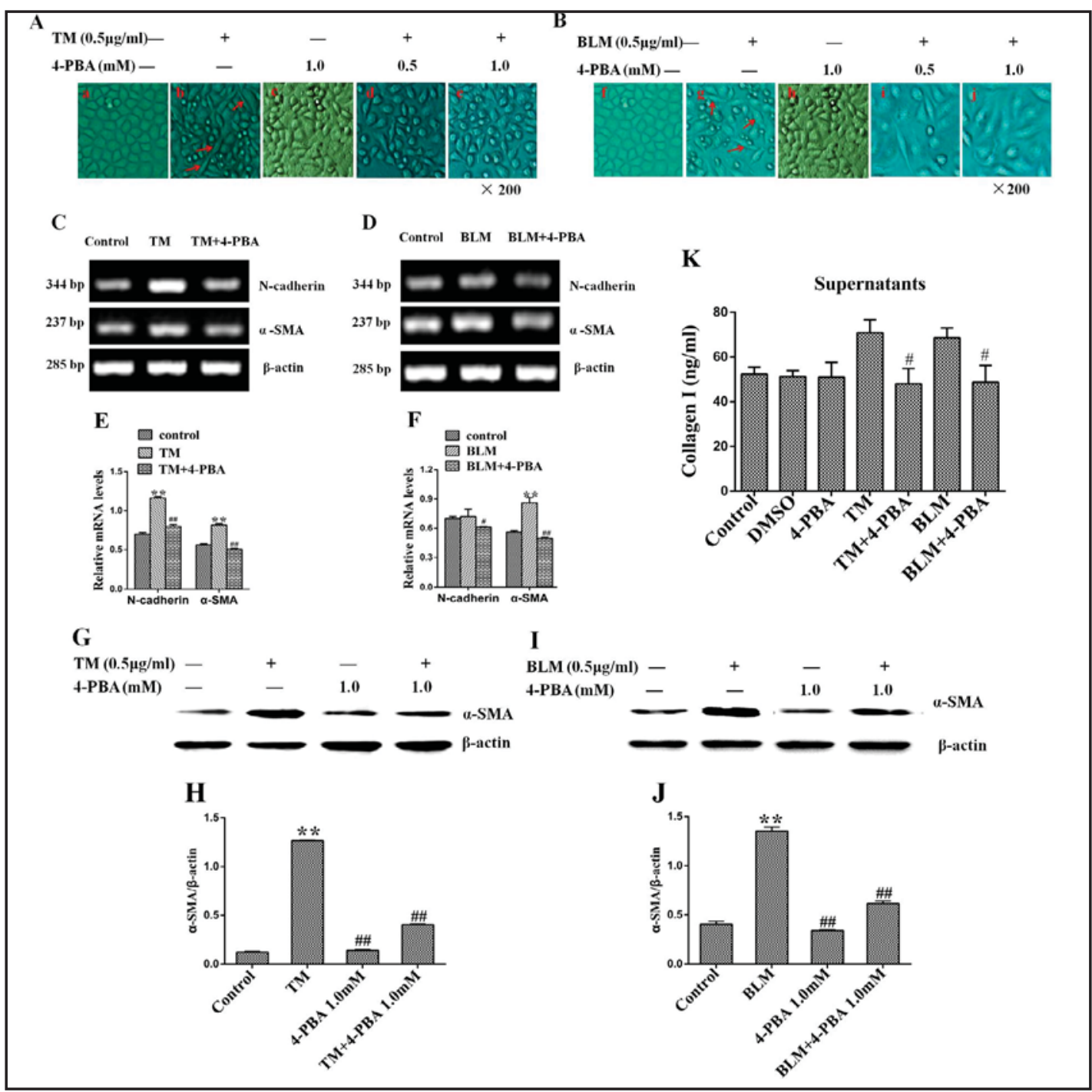

Fig. 3. ER stress induces EMT in A549 cells. A549 cells were plated at $1 \times 10^{6}$ cells/well in 6-well plates one day prior to treatment with TM or BLM, then the cells were growth arrested in serum-free medium for 24 h. A, B: Phase contrast images of A549 cells treated with TM or BLM for $48 \mathrm{~h}$ with or without pretreatment with 4-PBA. C, D, E, F: RT-PCR analysis of N-cadherin and $\alpha$-SMA mRNA levels in A549 cells treated with TM $(0.5 \mu \mathrm{g} / \mathrm{ml})$ or BLM $(0.5 \mu \mathrm{g} / \mathrm{ml})$ for $48 \mathrm{~h}$ with or without pretreatment with 4-PBA $(0.5 \mathrm{mM})$. G, H, I, J: Western blot analysis of $\alpha$-SMA in A549 cells treated with TM or BLM for $48 \mathrm{~h}$ with or without pretreatment with 4-PBA. K: ELISA analysis of collagen I level in the supernatant of A549 cells treated with TM $(0.5 \mu \mathrm{g} /$ $\mathrm{ml})$ or BLM $(0.5 \mu \mathrm{g} / \mathrm{ml})$ for $48 \mathrm{~h}$ with or without pretreatment with 4-PBA $(0.5 \mathrm{mM})$. All data were from 3 separate experiments. ${ }^{*} \mathrm{p}<0.05,{ }^{* *} \mathrm{p}<0.01$ vs. control. $\# \mathrm{p}<0.05$, \#\#p<0.05 vs. TM or BLM. TM: tunicamycin; BLM: bleomycin.

\section{Tunicamycin and bleomycin upregulate HDACs in A549 cells}

Next we explored whether HDAC activation is involved in tunicamycin and bleomycin induced ER stress in A549 cells. RT-PCR analysis showed that HDAC2 and HDAC6 mRNA levels increased after bleomycin treatment, while only HDAC2 mRNA levels increased after tunicamycin treatment in A549 cells (Fig. 4A, B). Similarly, Western blot analysis showed that HDAC2 and HDAC6 protein levels increased after tunicamycin and bleomycin treatment in A549 cells (Fig. 4C, D). These data indicate that tunicamycin and bleomycin upregulate HDACs in A549 cells. 


\begin{tabular}{|c|c|c|}
\hline & & \\
\hline 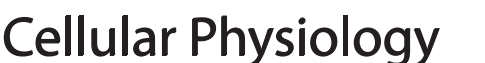 & Cell Physiol Biochem 2018; & $6: 1821-1834$ \\
\hline and Biochemistry & $\begin{array}{l}\text { DOI: } 10.1159 / 000489367 \\
\text { Published onIIne: April 30, } 2018\end{array}$ & $\begin{array}{l}\text { O } 2018 \text { The Author(s). Published by S. Karger AG, Basel } \\
\text { www.karger.com/cpb }\end{array}$ \\
\hline
\end{tabular}

Liu et al.: HDACs Promotes EMT of Lung Epithelium

Tunicamycin and bleomycin induce ER stress by upregulating HDACS

To reveal the association between HDACs and ER stress in A549 cells induced by tunicamycin or bleomycin, we detected tunicamycin or bleomycin induced ER stress in A549 cells treated by pan-HDAC inhibitor SAHA. Compared with tunicamycin group or bleomycin group, additional treatment with SAHA or 4-PBA decreased HDAC2 and HDAC6 mRNA expression (Fig. 5A, B, E, F). Furthermore, SAHA inhibited tunicamycin or bleomycin induced upregulation of GRP78 mRNA level in A549 cells (Fig. 5C, D, G, H). Similarly, Western blot analysis showed that SAHA or 4-PBA decreased tunicamycin or bleomycin induced upregulation of HDAC2 and HDAC6 protein levels and there was no significant difference in HDAC2 and HDAC6 protein expression between control group and 4-PBA or SAHA treated group (Fig. 5I, J, M, N). Furthermore, SAHA inhibited tunicamycin or bleomycin induced upregulation of GRP78 protein levels in A549 cells but there was no significant difference in GRP78 protein expression between control group and SAHA treated group (Fig. 5K, L, O, P). Collectively, these results indicate that tunicamycin and bleomycin may induce ER stress in A549 cells via the upregulation of HDAC2 and HDAC6 expression.

\section{HDACs inhibitor inhibits tunicamycin or bleomycin induced EMT}

Next we examined the effect of SAHA on tunicamycin or bleomycin induced EMT of A549 cells. Compared with tunicamycin group or bleomycin group, additional treatment with SAHA $(0.3$ and $1.0 \mu \mathrm{M})$ or treatment with SAHA $(0.3 \mu \mathrm{M})$ alone promoted elongated fibroblastic morphology change of cells (Fig. 6A, B). Meanwhile, $0.3 \mu \mathrm{M}$ SAHA inhibited tunicamycin or bleomycin induced upregulation of mesenchymal markers $\alpha$-SMA and also inhibited tunicamycin induced upregulation of mesenchymal marker N-cadherin at mRNA levels in A549 cells (Fig. 6C, D, E, F). Similarly, Western blot analysis showed that SAHA

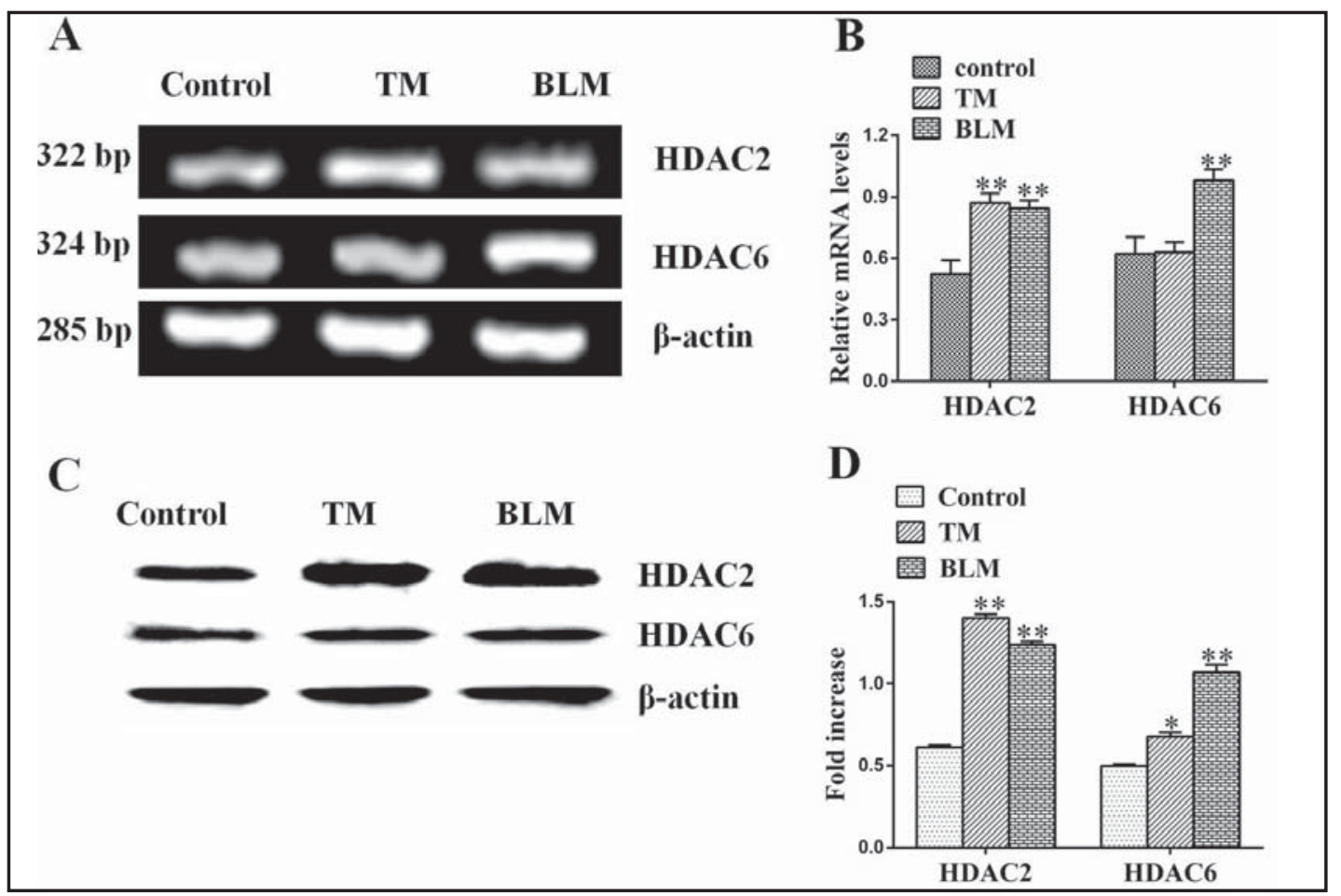

Fig. 4. Tunicamycin and bleomycin induce the expression of HDAC2 and HDAC6 in A549 cells. A549 cells were plated at $1 \times 10^{6}$ cells/well in 6 -well plates one day prior to treatment with TM or BLM, and the cells were growth arrested in serum-free medium for $24 \mathrm{~h}$. Then A549 cells were exposed to TM $(0.5 \mu \mathrm{g} / \mathrm{ml})$, BLM $(0.5 \mu \mathrm{g} / \mathrm{ml})$ or DMSO (control) for $48 \mathrm{~h}$. A, B: RT-PCR analysis of HDAC2 and HDAC6 mRNA levels in A549 cells. C, D: Western blot analysis of HDAC2 and HDAC6 protein levels in A549 cells. All data were from 3 separate experiments. ${ }^{*} \mathrm{p}<0.05,{ }^{* *} \mathrm{p}<0.01$ vs. control. TM: tunicamycin; BLM: bleomycin. 

Cellular Physiology Cell Physiol Biochem 2018;46:1821-1834 \begin{tabular}{c|c|c|}
\hline DOI: 10.1159/000489367 & O 2018 The Author(s). Published by S. Karger AG, Basel \\
\hline
\end{tabular} and Biochemistry Publisned onIIne: April 30, 2018 www.karger.com/cpb

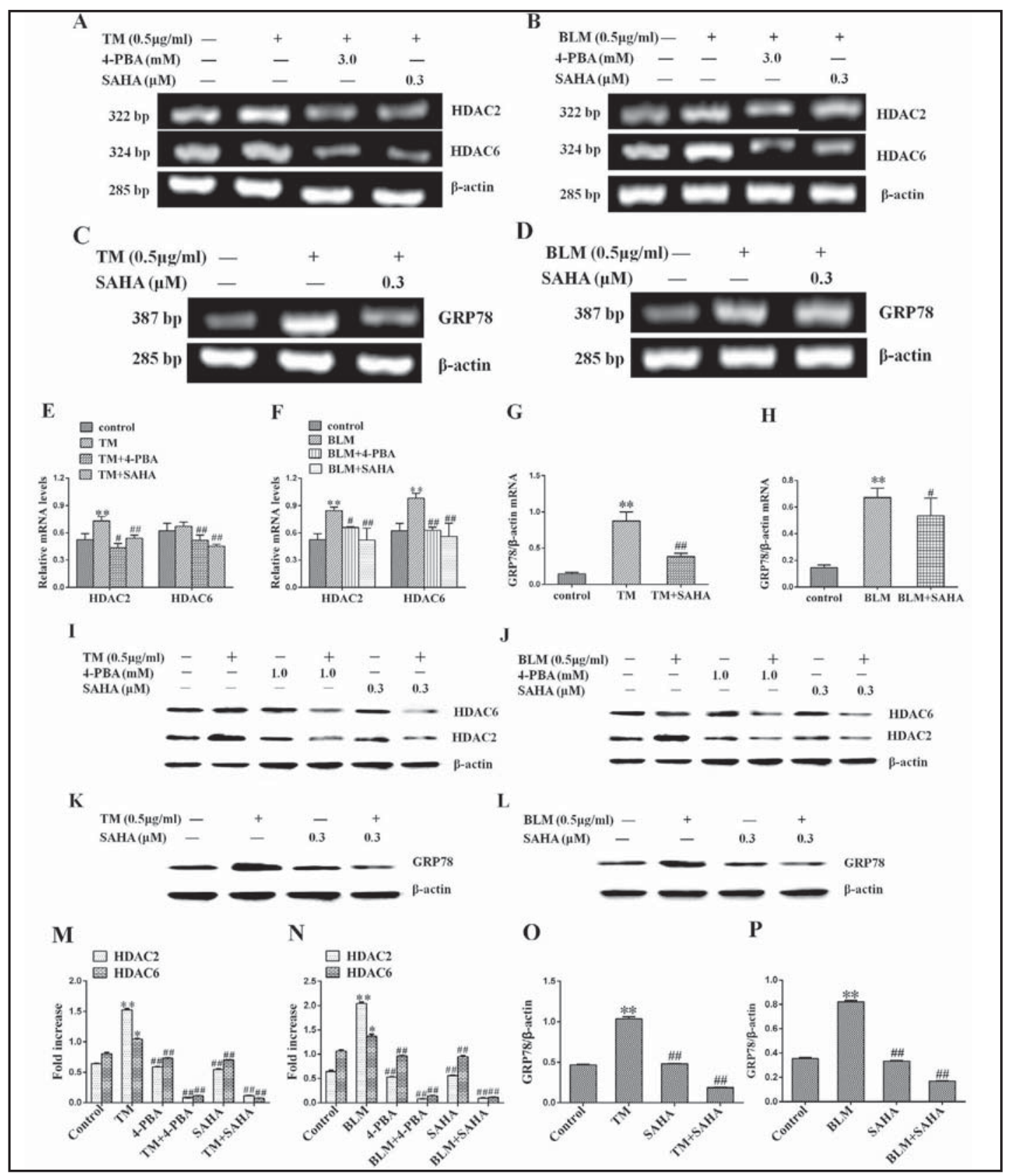

Fig. 5. Tunicamycin and bleomycin induce ER stress by upregulating HDACs. A549 cells were plated in 6-well plates and growth arrested in serum-free medium for $24 \mathrm{~h}$. A, B, E, F: RT-PCR analysis of HDAC2 and HDAC6 mRNA in A549 cells treated with TM or BLM for $48 \mathrm{~h}$ with or without pretreatment with SAHA or 4-PBA. C, D, G, H: RT-PCR analysis of GRP78 mRNA in A549 cells treated with TM or BLM for $48 \mathrm{~h}$ with or without pretreatment with SAHA or 4-PBA. I, J, M, N: Western blot analysis of HDAC2 and HDAC6 protein levels in A549 cells treated with TM or BLM for $48 \mathrm{~h}$ with or without pretreatment with SAHA or 4-PBA. K, L, O, P: Western blot analysis of GRP78 protein levels in A549 cells treated with TM or BLM for $48 \mathrm{~h}$ with or without pretreatment with SAHA or 4-PBA. All data were from 3 separate experiments. ${ }^{*} \mathrm{p}<0.05,{ }^{* *} \mathrm{p}<0.01$ vs. control. $\# \mathrm{p}<0.05, \# \# \mathrm{p}<0.05$ vs. TM or BLM. TM: tunicamycin; BLM: bleomycin.

decreased tunicamycin or bleomycin induced upregulation of $\alpha$-SMA at protein level but there was no significant difference in $\alpha$-SMA protein expression between control group and SAHA treated group (Fig. 6G, H, I, J). In addition, SAHA inhibited tunicamycin or bleomycin KARGER 


\section{Cellular Physiology Cell Physiol Biochem 2018;46:1821-1834 \begin{tabular}{l|l|l} 
DOI: 10.1159/000489367 & () 2018 The Author(s). Published by S. Karger AG, Basel \\
www Biochemistry
\end{tabular} Liu et al.: HDACs Promotes EMT of Lung Epithelium}

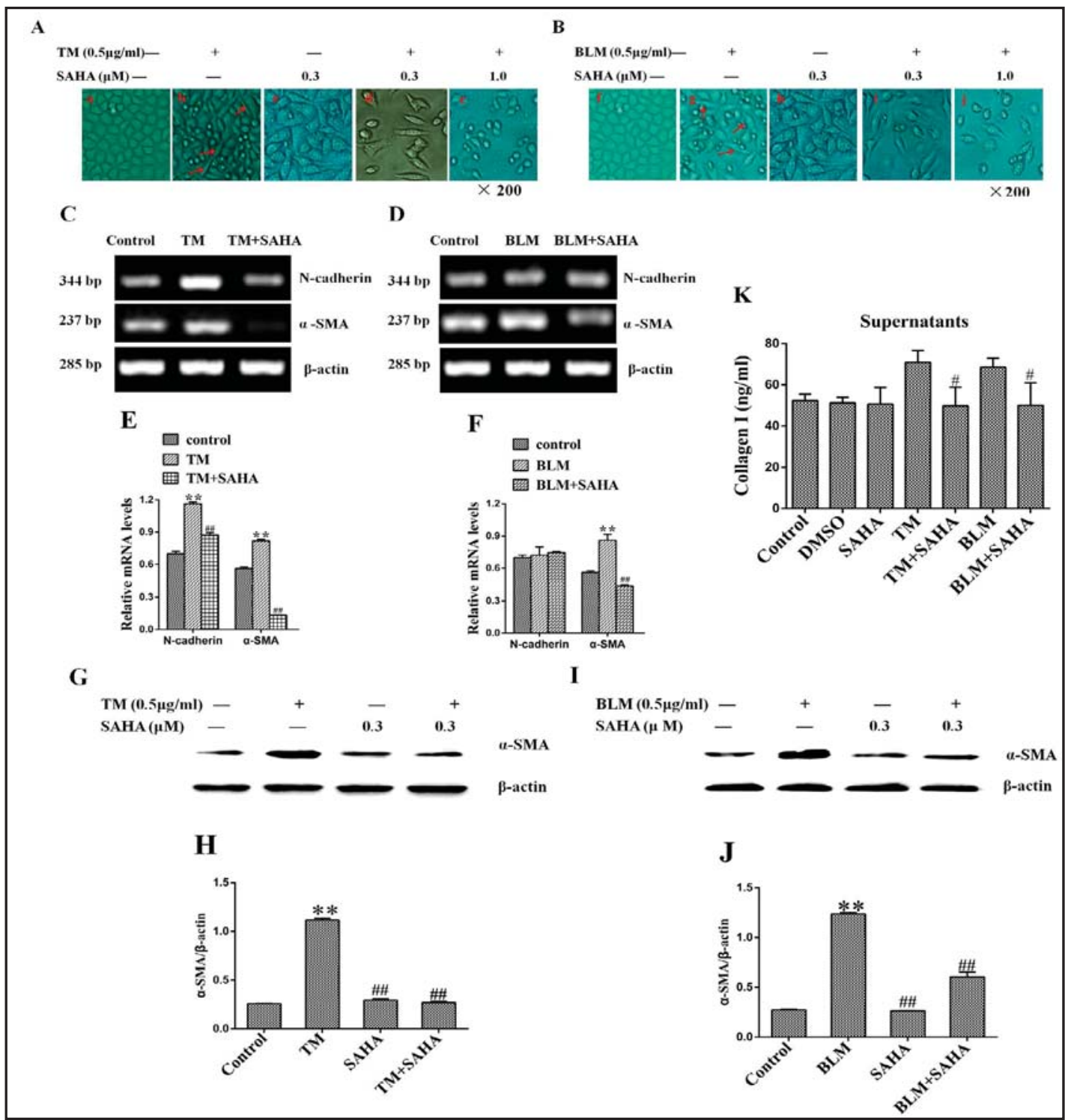

Fig. 6. SAHA inhibits tunicamycin or bleomycin induced EMT. A549 cells were plated at $1 \times 10^{6}$ cells/well in 6-well plates one day prior to treatment with TM or BLM, and cells were growth arrested in serum-free medium for 24 h. A, B: Phase contrast images of A549 cells incubated with TM or BLM for 48 h with or without pretreatment with SAHA. C, D, E, F: RT-PCR analysis of N-cadherin and $\alpha$-SMA mRNA levels in A549 cells treated with TM $(0.5 \mu \mathrm{g} / \mathrm{ml})$ or BLM $(0.5 \mu \mathrm{g} / \mathrm{ml})$ for $48 \mathrm{~h}$ with or without pretreatment with SAHA $(0.3$ $\mu \mathrm{M})$. G, H, I, J: Western blot analysis of $\alpha$-SMA in A549 cells treated with TM or BLM for $48 \mathrm{~h}$ with or without pretreatment with SAHA. K: ELISA analysis of collagen I level in the supernatant of A549 cells treated with TM $(0.5 \mu \mathrm{g} / \mathrm{ml})$ or BLM $(0.5 \mu \mathrm{g} / \mathrm{ml})$ for $48 \mathrm{~h}$ with or without pretreatment with SAHA $(0.3 \mathrm{mM})$. All data were from 3 separate experiments. ${ }^{*} \mathrm{p}<0.05,{ }^{* *} \mathrm{p}<0.01$ vs. control. $\# \mathrm{p}<0.05$, \#\#p<0.05 vs. TM or BLM. TM: tunicamycin; BLM: bleomycin.

induced secretion of Collagen I by A549 cells (Fig. 6K). Taken together, these results suggest that HDACs mediate tunicamycin or bleomycin induced EMT of A549 cells.

HDACs inhibitor inhibits ER stress induced upregulation of pulmonary fibrosis factors and the activation of Smad pathway

To explore whether ER stress affects the expression of fibrosis-related factors, we detected the expression of relevant factors at mRNA and protein levels by RT-PCR and ELISA. 

Cellular Physiology Cell Physiol Biochem 2018;46:1821-1834 \begin{tabular}{c|c|c|}
\hline DOI: 10.1159/000489367 & O 2018 The Author(s). Published by S. Karger AG, Basel \\
\hline and Biochemistry
\end{tabular} Liu et al.: HDACs Promotes EMT of Lung Epithelium

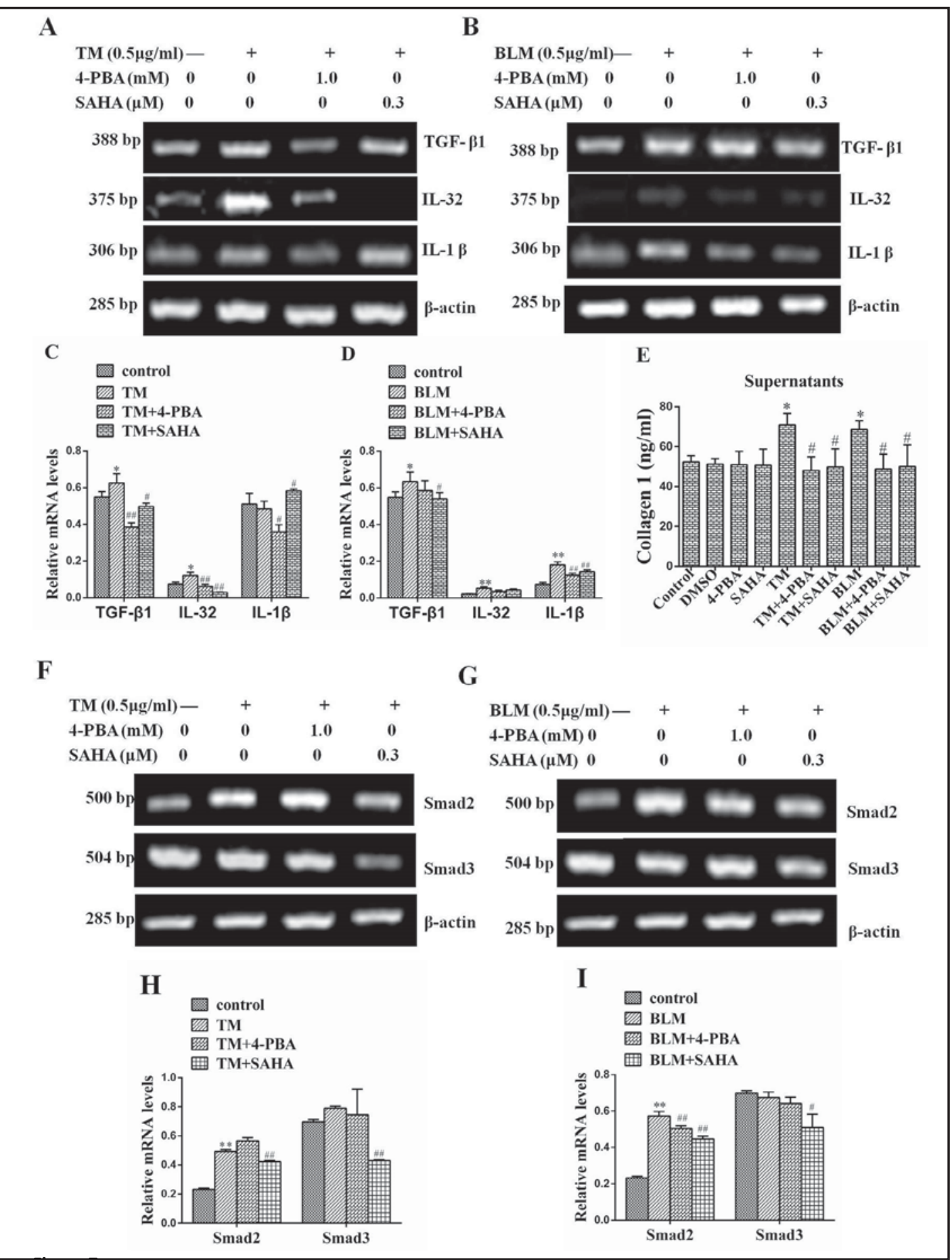

Fig. 7. SAHA inhibits the upregulation of pulmonary fibrosis factors and the activation of Smad pathway. A549 cells were plated in 6-well plates and growth arrested in serum-free medium for $24 \mathrm{~h}$. A, B, C, D: RT-PCR analysis of TGF- $\beta 1$, IL-32 and IL-1 $\beta$ mRNA in A549 cells treated with TM or BLM for $24 \mathrm{~h}$ with or without pretreatment with SAHA or 4-PBA. E: ELISA analysis of TGF- $\beta 1$ levels in the supernatant of A549 cells treated with TM $(0.5 \mu \mathrm{g} / \mathrm{ml})$ or BLM $(0.5 \mu \mathrm{g} / \mathrm{ml})$ for $48 \mathrm{~h}$ with or without pretreatment with SAHA $(0.3$ $\mu \mathrm{M})$ or 4-PBA (1.0 mM). F, G, H, I: RT-PCR analysis of Smad2 and Smad3 mRNA levels in A549 cells treated with TM or BLM for $48 \mathrm{~h}$ with or without pretreatment with SAHA or 4-PBA. All data were from 3 separate experiments. ${ }^{*} \mathrm{p}<0.05,{ }^{* *} \mathrm{p}<0.01$, vs. control; $\# \mathrm{p}<0.05$, \#\#p<0.05 vs. TM or BLM. TM: tunicamycin; BLM: bleomycin. 


\section{Cellular Physiology Cell Physiol Biochem 2018;46:1821-1834 and Biochemistry Publisned online: April 30, $2018 \quad \begin{aligned} & \text { O 2018 The Authors. } \\ & \text { www.karger.com/cpb }\end{aligned}$}

Liu et al.: HDACs Promotes EMT of Lung Epithelium

The results showed that tunicamycin increased TGF- $\beta 1$ and IL-32 mRNA expression levels as well as the secretion of TGF- $\beta 1$ protein in A549 cells, while bleomycin increased TGF- $\beta 1$, IL-32 and IL-1 $\beta$ mRNA expression levels as well as the secretion of TGF- $\beta 1$ protein in A549 cells (Fig. 7A, B, C, D, E). However, the changes induced by tunicamycin or bleomycin could be antagonized by 4-PBA or SAHA (Fig. 7A, B, C, D, E).

Next, we examined the effects of ER inhibitor and HDACs inhibitor on TGF- $\beta 1 / \mathrm{Smad}$ pathway in A549 cells. RT-PCR analysis showed that tunicamycin and bleomycin increased the expression of Smad2 mRNA but had no significant effects on the expression of Smad3 mRNA, compared to control group (Fig. 7F, G, H, I). SAHA inhibited Smad3 mRNA expression and the upregulation of Smad2 mRNA levels induced by tunicamycin or bleomycin, but 4-PBA only inhibited the upregulation of Smad2 mRNA level induced by bleomycin (Fig. 7F, G, H, I). In summary, these results indicate that HDACs mediate the upregulation of pulmonary fibrosis factors and the activation of Smad pathway after ER stress.

\section{Discussion}

Pulmonary fibrosis is a complex pathological process, and pulmonary EMT is one of the important mechanisms underlying its pathogenesis. Lung myofibroblast cells are mainly derived from EMT of alveolar epithelial cells. However, current understanding of pulmonary EMT remains limited. Recent studies showed that in the pathogenesis of pulmonary fibrosis, certain genetic and environmental factors such as smoking, chronic aspiration, viral infection, mucin 5B gene promoter polymorphism, telomerase gene mutation, SPC and SPA mutations may stimulate ER stress in alveolar epithelial cells, leading to the occurrence of EMT [9-11]. In mouse lung fibrosis, bleomycin induced ER stress, which then mediated the progression of EMT [16]. In agreement with previous findings, in this study we demonstrated that tunicamycin and bleomycin induced ER stress in alveolar epithelial cells, and ER stress caused EMT in alveolar epithelial cells.

HDACs are crucially implicated in many physiological and pathological processes, and HDACs inhibitor could benefit cancer and fibrotic diseases. In certain tumor cells, HDACs localized in ER affect the occurrence of ER stress [21-23]. In this study, we provided the first evidence that tunicamycin and bleomycin induced ER stress in alveolar epithelial cells via the upregulation of HDAC2/6, which mediate the formation of EMT. However, whether other types of HDACs are involved in ER stress induced EMT needs to be further explored. A very recent study suggested that class I HDACs (HDAC1, 2, 3 and 8) play a major role to regulate EMT of human renal epithelial cells, while class IIa HDACs (HDAC4 and 5) are unlikely to be involved [24]. In addition, HDAC inhibitor SB939 inhibited EMT of human renal proximal tubular epithelial cells, and reduced the accumulation of $\alpha$-SMA and inflammatory and profibrotic cytokines. The mechanism may be due to the inhibition of Smad-independent TGF- $\beta$ signaling by HDAC inhibitor and involve MAPK and PI3K/AKT pathways [25]. Apart from being an ER stress inhibitor, 4PBA also acts as an HDAC inhibitor (class I and II) when used at higher doses. In this study we found that 4PBA did not cause significant changes in the levels of HDAC 2 and 6, perhaps because we used low dose of 4PBA. These data provide strong support that HDACs inhibitor inhibits ER stress induced EMT and the upregulation of pulmonary fibrosis factors.

The signaling mechanisms involved in ER stress induced EMT are complex. ER stress induced EMT in alveolar epithelial cells through Smad2 and Src pathways [14]. In this study we found that ER stress increased Smad2 but not Smad3 mRNA levels, but HDACs inhibitor SAHA inhibited the expression of Smad2 and Smad3 mRNAs. Thus, Smad2 pathway may be involved in ER stress and EMT in alveolar epithelial cells induced by tunicamycin and bleomycin. However, a recent study showed that TGF- $\beta$ mediated EMT in retinal pigment epithelium through complex interplay between Smad pathway, Akt, p38MAPK, ERK1/2 pathways and Jagged/Notch pathway [26]. In addition, miR-145 was recently reported to modulate TGF- $\beta 1$ /Smad3 signaling to regulate endothelial-to-mesenchymal transition 


\section{Cellular Physiology Cell Physiol Biochem 2018;46:1821-1834 \begin{tabular}{ll|l} 
aOI: 10.1159/000489367 & $\begin{array}{l}\text { ( ) 2018 The Author(s). Published by S. Karger AG, Basel } \\
\text { www.karger.com/cpb }\end{array}$ \\
\hline
\end{tabular} Liu et al.: HDACs Promotes EMT of Lung Epithelium}

Fig. 8. Proposed mechanisms by which tunicamycin and bleomycin cause pulmonary fibrosis. Tunicamycin and bleomycin upregulate HDAC2/6, which then induce ER stress in alveolar epithelial cells. Next, ER stress activates $\operatorname{Smad} 2 / 3$ pathway and promotes EMT of alveolar epithelial cells. The accumulation of $\alpha$-SMA and the release of inflammatory and pro-fibrotic cytokines contribute to pulmonary fibrosis. HDACs inhibitors such as SAHA or ER stress inhibitors such as 4-BPA inhibit tunicamycin and bleomycin induced ER stress, and block the activation of Smad pathway and EMT to prevent pulmonary fibrosis.

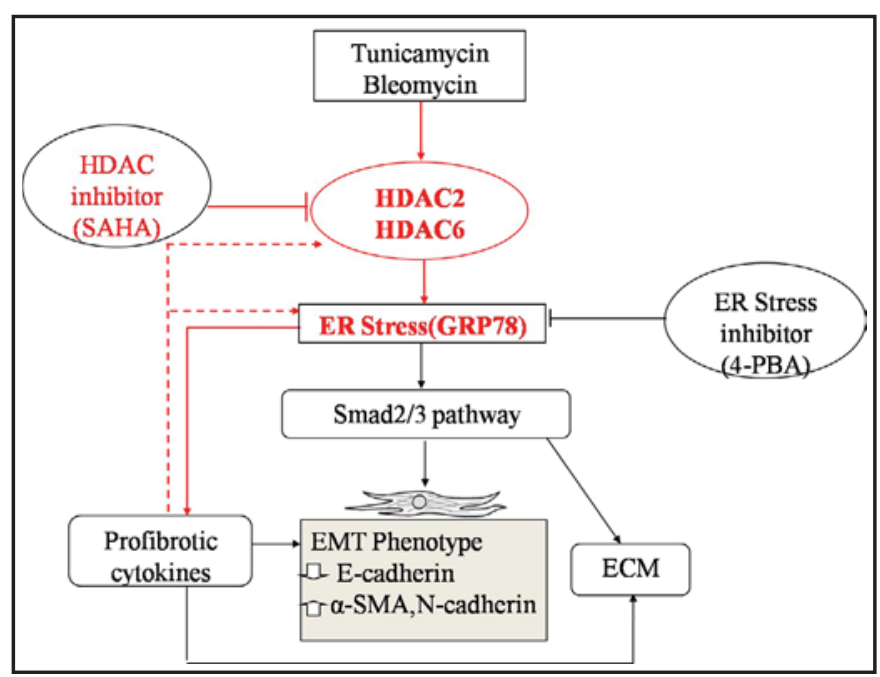

[27]. Further studies are necessary to investigate the crosstalk of Smad pathway with other pathways in mediating EMT of alveolar epithelial cells exposed to ER stress.

During pulmonary fibrosis, the expression of pro-fibrotic factors and anti-fibrotic factors is upregulated and downregulated, respectively. Pro-fibrotic factors such as TGF- $\beta 1$, IL-1 $\beta$, TNF- $\alpha$, IL-17, IL-27, IL-13 and IL-32 were highly expressed in pulmonary fibrosis [28, 29]. ER stress can promote the expression and secretion of TGF- $\beta 1$ in lung epithelial cells, and plays an important role in the progression of pulmonary fibrosis [30]. In this study we found that tunicamycin and bleomycin induced ER stress by upregulating HDACs, which then promoted the expression of TGF- $\beta 1$, IL-32 and IL- $1 \beta$. These pro-fibrotic factors may contribute to pulmonary fibrosis.

\section{Conclusion}

We provide the first evidence that tunicamycin and bleomycin induce ER stress via upregulating HDACs in alveolar epithelial cells. ER stress then activates Smad2/3 pathway and promotes EMT of alveolar epithelial cells. Consequently, the accumulation of $\alpha$-SMA and the release of inflammatory and pro-fibrotic cytokines will lead to pulmonary fibrosis. However, HDACs inhibitor or ER stress inhibitor could inhibit ER stress induced by tunicamycin and bleomycin, and block the activation of Smad pathway and EMT, thus preventing pulmonary fibrosis (Fig. 8). These results suggest that HDACs promote ER stress induced EMT in human alveolar epithelial cells, and HDACs inhibitors are promising agents for the therapy of pulmonary fibrosis.

\section{Acknowledgements}

This study was supported by grants from Guizhou Province Health Department (No. gzwjkj2014-1-064), Guizhou Province Health Department (No. gzwjkj2015-1-017) and Science and Technology Agency of Guizhou Province (No. branch of Guizhou talent team 2015-4018).

\section{Disclosure Statement}

No conflict of interests exists. 


\section{Cellular Physiology Cell Physiol Biochem 2018;46:1821-1834

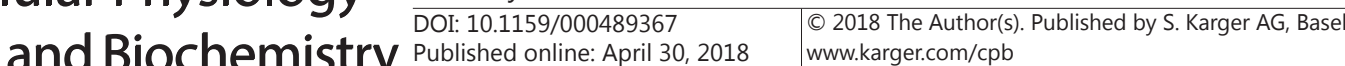

Liu et al.: HDACs Promotes EMT of Lung Epithelium

\section{References}

1 Raghu G, Freudenberger TD, Yang S, Curtis JR, Spada C, Hayes J, Sillery JK, Pope CE 2nd, Pellegrini CA: High prevalence of abnormal acid gastro-oesophageal reflux in idiopathic pulmonary fibrosis. Eur Respir J 2006;27:136-142.

-2 Nalysnyk L, Cid-Ruzafa J, Rotella P, Esser D: Incidence and prevalence of idiopathic pulmonary fibrosis: review of the literature. Eur Respir Rev 2012;21:355-361.

-3 Antoniou KM, Margaritopoulos GA, Siafakas NM: Pharmacological treatment of idiopathic pulmonary fibrosis: from the past to the future. Eur Respir Rev 2013;22:281-291.

-4 Todd NW, Luzina IG, Atamas SP: Molecular and cellular mechanisms of pulmonary fibrosis. Fibrogenesis Tissue Repair 2012;5:11.

5 Nho RS: Current Concept for the Pathogenesis of Idiopathic Pulmonary Fibrosis. Clin Res Pulmonol 2013;1:1008.

6 Wolters PJ, Collard HR, Jones KD: Pathogenesis of idiopathic pulmonary fibrosis. Annu Rev Pathol 2014;9:157-179.

7 Kage H, Borok Z: EMT and interstitial lung disease: a mysterious relationship. Curr Opin Pulm Med 2012;18:517-523.

8 Alipio ZA, Jones N, Liao W, Yang J, Kulkarni S, Sree Kumar K, Hauer-Jensen M, Ward DC, Ma Y, Fink LM: Epithelial to mesenchymal transition induced by bleomycin or TFG(b1)/EGF in murine induced pluripotent stem cell-derived alveolar Type II-like cells. Differentiation 2011;82:89-98.

9 Park S, Lee EJ: Recent advances in idiopathic pulmonary fibrosis. Tuberc Respir Dis (Seoul) 2013;74:1-6.

10 Lawson WE, Crossno PF, Polosukhin VV, Roldan J, Cheng DS, Lane KB, Blackwell TR, Xu C, Markin C, Ware LB, Miller GG, Loyd JE, Blackwell TS: Endoplasmic reticulum stress in alveolar epithelial cells is prominent in IPF: association with altered surfactant protein processing and herpesvirus infection. Am J Physiol Lung Cell Mol Physiol 2008;294:L1119-1126.

-11 Kropski JA, Lawson WE, Blackwell TS: Right place, right time: the evolving role of herpesvirus infection as a "second hit" in idiopathic pulmonary fibrosis. Am J Physiol Lung Cell Mol Physiol 2012;302:L441-444.

12 Basseri S, Lhoták S, Sharma AM, Austin RC: The chemical chaperone 4-phenylbutyrate inhibits adipogenesis by modulating the unfolded protein response. J Lipid Res 2009;50:2486-2501.

13 Zhong Q, Zhou B, Ann DK, Minoo P, Liu Y, Banfalvi A, Krishnaveni MS, Dubourd M, Demaio L, Willis BC, Kim KJ, duBois RM, Crandall ED, Beers MF, Borok Z: Role of endoplasmic reticulum stress in epithelialmesenchymal transition of alveolar epithelial cells: effects of misfolded surfactant protein. Am J Respir Cell Mol Biol 2011;45:498-509.

14 Tanjore H, Cheng DS, Degryse AL, Zoz DF, Abdolrasulnia R, Lawson WE, Blackwell TS: Alveolar epithelial cells undergo epithelial-to-mesenchymal transition in response to endoplasmic reticulum stress. J Biol Chem 2011;286:30972-30980.

15 Moon SY, Kim HS, Nho KW, Jang YJ, Lee SK: Endoplasmic reticulum stress induces epithelial-mesenchymal transition through autophagy via activation of c-Src kinase. Nephron Exp Nephrol 2014;126:127-140.

16 Zhao H, Qin HY, Cao LF, Chen YH, Tan ZX, Zhang C, Xu DX: Phenylbutyric acid inhibits epithelialmesenchymal transition during bleomycin-induced lung fibrosis. Toxicol Lett 2015;232:213-220.

17 Kahali S, Sarcar B, Chinnaiyan P: The emerging role of histone deacetylases (HDACs) in UPR regulation. Methods Enzymol 2011;490:159-174.

-18 Cho JS, Moon YM, Park IH, Um JY, Kang JH, Kim TH, Lee SH, Kang HJ, Lee HM: Effects of histone deacetylase inhibitor on extracellular matrix production in human nasal polyp organ cultures. Am J Rhinol Allergy 2013;27:18-23.

19 Luo F, Zhuang Y, Sides MD, Sanchez CG, Shan B, White ES, Lasky JA: Arsenic trioxide inhibits transforming growth factor- $\beta 1$-induced fibroblast to myofibroblast differentiation in vitro and bleomycin induced lung fibrosis in vivo. Respir Res 2014;15:51.

20 Xiao W, Chen X, Liu X, Luo L, Ye S, Liu Y: Trichostatin A, a histone deacetylase inhibitor, suppresses proliferation and epithelial-mesenchymal transition in retinal pigment epithelium cells. J Cell Mol Med 2014;18:646-655.

-21 Kahali S, Sarcar B, Fang B, Williams ES, Koomen JM, Tofilon PJ, Chinnaiyan P: Activation of the unfolded protein response contributes toward the antitumor activity of vorinastat. Neoplasia 2010;12:80-86. 


\section{Cellular Physiology Cell Physiol Biochem 2018;46:1821-1834 \begin{tabular}{ll|l} 
DOI: 10.1159/000489367 & $\begin{array}{l}\text { () 2018 The Author(s). Published by S. Karger AG, Basel } \\
\text { www.karger.com/cpb }\end{array}$
\end{tabular}}

Liu et al.: HDACs Promotes EMT of Lung Epithelium

22 Rao R, Nalluri S, Kolhe R, Yang Y, Fiskus W, Chen J, Ha K, Buckley KM, Balusu R, Coothankandaswamy V, Joshi A, Atadja P, Bhalla KN: Treatment with panobinostat induces Glucose-Regulated Protein 78 acetylation and endoplasmic reticulum stress in breast cancer cells. Mol Cancer Ther 2010;9:942-952.

23 Kahali S, Sarcar B, Prabhu A, Seto E, Chinnaiyan P: Class I histone deacetylases localize to the endoplasmic reticulum and modulate the unfolded protein response. FASEB J 2012;26: 2437-2445.

24 Choi SY, Kee HJ, Kurz T, Hansen FK, Ryu Y, Kim GR, Lin MQ Jin L, Piao ZH, Jeong MH: Class I HDACs specifically regulate E-cadherin expression in human renal epithelial cells. J Cell Mol Med 2016;20:22892298.

-25 Kang SW, Lee SM, Kim JY, Kim SY, Kim YH, Kim TH, Kang MS, Jang WH, Seo SK: Therapeutic activity of the histone deacetylase inhibitor SB939 on renal fibrosis. Int Immunopharmacol 2017;42:25-31.

26 Chen X, Xiao W, Wang W, Luo L, Ye S, Liu Y: The complex interplay between ERK1/2, TGF $\beta /$ Smad, and Jagged/Notch signaling pathways in the regulation of epithelial-mesenchymal transition in retinal pigment epithelium cells. PLoS One 2014;9:e96365.

27 Xiang Y, Zhang Y, Tang Y, Li Q: MALAT1 Modulates TGF-B1-Induced Endothelial-to-Mesenchymal Transition through Downregulation of miR-145. Cell Physiol Biochem 2017;42:357-372.

-28 Dong S, Zhang X, He Y, Xu F, Li D, Xu W, Wang H, Yin Y, Cao J: Synergy of IL-27 and TNF- $\alpha$ in regulating CXCL10 expression in lung fibroblasts. Am J Respir Cell Mol Biol 2013;48:518-530.

29 Li D, Chen D, Zhang X, Wang H, Song Z, Xu W, He Y, Yin Y, Cao J: JNK and Akt signaling pathways regulating TNF- $\alpha$-induced IL-32 expression in human lung fibroblasts: implications in airway inflammation. Immunology 2015;144:282-290.

-30 Maitra M, Cano CA, Garcia CK: Mutant surfactant A2 proteins associated with familial pulmonary fibrosis and lung cancer induce TGF- $\beta 1$ secretion. Proc Natl Acad Sci USA 2012;109:21064-21069. 